\title{
Heating and cooling hybrid system and method for its calculation and design
}

\author{
Zohrab Melikyan \\ Armenia National University of Architecture and Construction, HVAC and Energy, Yerevan, Armenia
}

\section{Email address:}

zohrabmelikyan@yahoo.com

\section{To cite this article:}

Zohrab Melikyan. Heating and Cooling Hybrid System and Method for Its Calculation and Design. International Journal of Energy and Power Engineering. Vol. 3, No. 6, 2014, pp. 296-307. doi: 10.11648/j.ijepe.20140306.13

\begin{abstract}
In this article newly developed heating and cooling hybrid system is discussed. The system combines a heat pump, heating boiler and solar air heater. Low temperature source of heat pump is a gas mixture composed of waste warm gases, like inside used ventilation air, flue gases of heating boiler (smock), as well as outside air, heated in solar air heater. The evaporator of heat pump is installed in waste warm gases mixing chamber, aiming at avoiding the main disadvantage of ordinary air sourced heat pump, in case of which the evaporator surface in wintertime is covered with ice crust that obstructs movement of air through the evaporator of heat pump. To solve the problem it is suggested to create a mixture of waste warm gases gathered in a gas mixing chamber and serving as heat source. A method for calculation and design of the new system was developed for both winter heating and summer cooling of a building. The energy and economic investigation based on mathematical model proved rather high cost effectiveness and energy efficiency of developed heating and cooling hybrid system.
\end{abstract}

Keywords: Hybrid System, Heat Pump, Heating Boiler, Solar Air Heater, Gases Mixing Chamber, Winter Heating, Summer Cooling, Cost Effectiveness, Energy Efficiency

\section{Introduction}

The new type hybrid system consists of heating boiler, heat pump, and lately developed solar air heater. As low temperature heat source of the heat pump, instead of outside air, is used a mixture of various warm waste gases, gathered from different parts of a building or surrounding objects and collected in a gas mixing chamber. The gas mixture comprises boiler's smock; ventilation used air evacuated from the building and outside air, heated in solar air heater. The temperature of warm gases mixture is much higher, than the temperature of wintertime outside air. In fact, a new heating and cooling system is developed the heat pump of which uses artificially created low temperature heat source. The simplified version of such system was published in $[4,6]$.

\section{Structure and Operation of Newly Developed Heating and Cooling Hybrid System}

The scheme of the heating and cooling hybrid system is represented in the Fig.1.

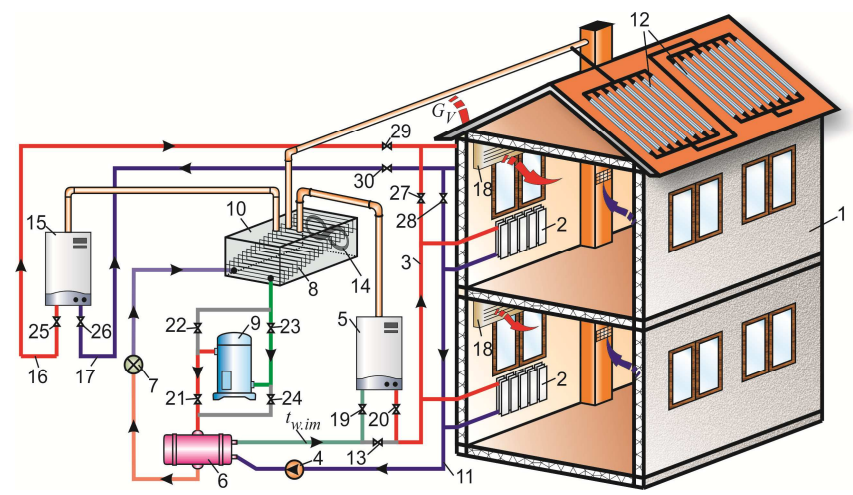

1- building; 2-fan-coils of heating system; 3-heat carrier distribution stands and pipes; 4-variable speed water circulation pump; 5- heating boiler; 6-condenser of heat pump; 7-throattling valve; 8 - evaporator of heat pump, located in gas mixing chamber; 9-compressor of heat pump; 10-gas mixing chamber; 11- return pipe of used and cooled heat carrier; 12- solar air heater modules; 13- by-pass valve; 14-exhaust fan of gas mixing chamber; 15-separate boiler for heating of ventilation fresh air; 16-hot water supply pipe to the ventilation air heating equipment; 17- return water pipe from ventilation equipment; 18-ventilation air heating heat exchanger; 19, 20-valves; 21, 22, 23,24 - bypass valves for reversing the refrigerant of heat pump; 25 , 26-valves of separate boiler; 27, 28, 29, 30-valves of ventilation system.

Figure 1. Scheme of heating and cooling hybrid system 
In heating season the hybrid system operates in two regimes: 1) daytime - sunshine period of heating season, 2) cloudy and nighttime period of heating season. In summertime the system can operate for summertime cooling of building too.

\section{Operation of the Hybrid System in Daytime - Sunshine Periods of Heating Season}

In mentioned period the system operates in the following way (see Fig.1): from fan-coils (2) of the house's heating system the used and cooled heating water at temperature $t_{w .1}$ returns from fan-coils to the condenser (6) of heat pump where is partially heated up to an intermediate temperature $t_{\text {w.int }}$. Then the warmed water from condenser is forced into the boiler (5) where is heated from intermediate temperature $t_{\text {w.int }}$ up to final temperature $t_{w .2}$. Afterwards the hot water is supplied from the boiler to fan-coils (2) where delivers heat to the air of inside space for covering the heating demand $Q_{h d}, \mathrm{~kW}$ of the house, which can be calculated by the help of method published in $[1,2]$. As a result, the temperature of the water in fan-coils drops from $t_{w .2}$ to $t_{w .1}$. In fact, the heating demand of the house is shared between the boiler and heat pump. To provide higher energy efficiency of the whole system the heat pump should cover the major portion of heating demand. The portion of heating demand covered by boiler $Q_{b}$ in sunshine period is determined by the following expression:

$$
Q_{b}=\beta Q_{h d}
$$

where:

$\beta=0.4$ - rate of heating demand portion covered by heating boiler in sunshine period.

Heating demand portion covered by the heat pump is the following:

$$
Q_{H P}=(1-\beta) Q_{h d}
$$

where:

$(1-\beta)=0.6$ - portion of heating demand to be covered by the heat pump.

To provide cost effectiveness of the whole hybrid system it is expedient to use air to air type simple and not expensive heat pump. However, in winter cold climate the evaporator of air-to-air heat pump can be covered by ice crust and can get out of order [1]. To escape freezing it is necessary to locate heat pump's evaporator (8) in a warm gaseous environment. For this purpose, in a gas-mixing chamber (10) warm waste gases mixture is collected. To heating outside fresh ventilation air, a separate boiler (15) is applied. For better understanding of operation of the hybrid system, it is necessary to follow the construction and operation of gas mixing chamber connected with other main parts of the system. The scheme of construction and operation of gas mixing chamber represents the Fig. 2 .

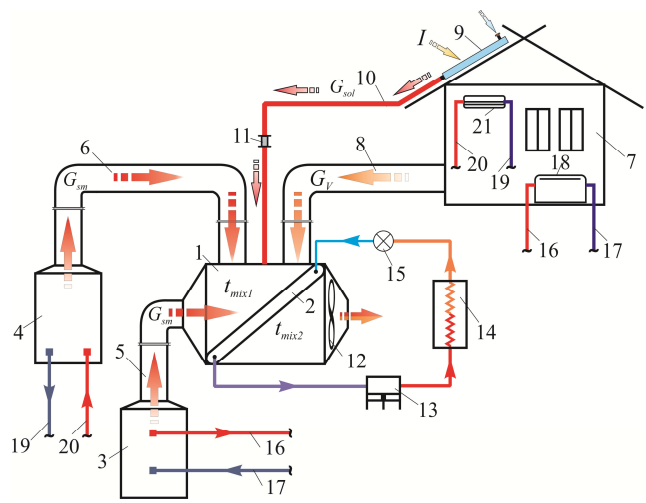

1-gas mixing chamber; 2-heat pump's evaporator; 3-heating boiler; 4-separate boiler for heating ventilation fresh air; 5, 6-chimneys of boilers; 7-building, 8-exhaust pipeline of ventilation used air; 9-solar air heater; 10-warm air supplying pipe from solar air heater; 11-valve; 12-gas mixture chamber exhaust fan; 13-compressor of heat pump; 14-condenser of heat pump; 15throttling (expansion) valve; 16-heat carrier supplying pipeline; 17- heat carrier return pipeline; 18-fan-coil; 19-heat carrier return pipeline from ventilation system; 20-heat carrier supplying pipeline to ventilation system; 21-heat exchanger for heating ventilation fresh air.

Figure 2. Scheme of construction and operation of gas mixing chamber connected with other main parts of the system

The gas-mixing chamber is an insulated metallic hermetic box (1), on the front edge of which the heating boiler's (3) chimney outlet (5) is connected. On the upper horizontal edge of the chamber are connected building's ventilation used air evacuation pipeline (8), supply pipeline (10) of solar air heater and separate boiler's (4) chimney outlet (6). On the backside edge, an exhaust fan (12) is fixed for evacuating used and cooled gas mixture. In the mixing chamber, the evaporator (2) of the heat pump is located. Evaporator divides the mixing chamber in warm and cooled gases sections. Into warm gases section enter flue hot gas (smock) of boilers, exhaust warm ventilation air and outside air, warmed in solar air heater (9). In the mixing chamber, the gas mixture acquires a total thermal potential $\Sigma Q_{m i x}, \mathrm{~kW}$ consisted of thermal potentials of separate gases. The thermal potential of each gas in the mixture $Q_{\text {gas.pot }}, \mathrm{kW}$ is determined by the following production:

$$
Q_{\text {gas.pot }}=G_{\text {gas.i }} \cdot C_{\text {gas.i }} \cdot t_{\text {gas. } i}
$$

where:

$G_{\text {gas.i }}-$ mass of each kind of gases, $\mathrm{kg} / \mathrm{s}$,

$C_{\text {gas.i }}$ - specific heat of each kind of gases, $\mathrm{kJ} / \mathrm{kg}^{\circ} \mathrm{C}$,

$t_{\text {gas. }}$ - $^{-}$temperature of each kind of gases, ${ }^{\circ} \mathrm{C}$.

The total thermal potential of gas mixture $\Sigma Q_{m i x}, \mathrm{~kW}$ in gas mixing chamber is the following production:

$$
\Sigma Q_{m i x}=G_{m i x} \cdot C_{m i x} \cdot t_{m i x .1}
$$

where:

$G_{m i x}$ - total mass of all kinds of gases in the mixing chamber, $\mathrm{kg} / \mathrm{s}$,

$C_{m i x}$ - average specific heat of gases, $\mathrm{kJ} / \mathrm{kg}^{\circ} \mathrm{C}$,

$t_{\text {mix.l }}$ - temperature, acquired by the mixture of gases, ${ }^{\circ} \mathrm{C}$.

Formula (4) allows finding the acquired initial temperature of gas mixture $t_{\text {mix.l }}$ by the following ratio: 


$$
t_{m i x .1}=\frac{\Sigma Q_{m i x}}{G_{m i x} \cdot C_{m i x}}
$$

To determine the value of $t_{\text {mix.l }}$ should be found values of $G_{m i x}$ and $\Sigma Q_{m i x}$ of the gas mixture. For this purpose, first the values of masses $G_{g a s}, \mathrm{~kg} / \mathrm{s}$ and thermal potentials $Q_{p o t}, \mathrm{~kW}$ of separate gases must be determined.

\section{Determination of Masses of Waste Warm Gases Collected in Gas Mixing Chamber}

Mass of flue gas (smock) $G_{s m}, \mathrm{~kg} / \mathrm{s}$ produced by heating and separate boilers depend on portion of heating demand, covered by the heating boiler ( $Q_{b}=\beta Q_{h d}$ ) and also by heat $Q_{V}$ produced by separate boiler for heating whole quantity of ventilation fresh air, for replacing completely extracted used ventilation air from the building. Therefore the mass of smock $G_{s m}, \mathrm{~kg} / \mathrm{s}$ entering into gas mixing chamber should be determined by the following equation which takes into account that burning of $1 \mathrm{~m}^{3}$ of natural gas produces $12 \mathrm{~m}^{3}$ of flue gas [8]:

$$
G_{s m}=12 \rho_{s m} \frac{\beta Q_{h d}+Q_{V}}{3600 \eta_{b} Q_{\text {gas }}}
$$

where: the quantity of heat $Q_{V}, \mathrm{~kW}$, produced by separate boiler for heating of ventilation fresh air from outside temperature $t_{\text {out }}$ to inside air temperature $t_{\text {in }}$ is determined by the following formula:

$$
Q_{V}=\frac{a \cdot b \cdot n \cdot 20 \cdot \rho_{\text {air }} C_{\text {air }}\left(t_{\text {in }}-t_{\text {out }}\right)}{9 \cdot 3600}
$$

where:

$\rho_{s m}$ - density of flue gas (smock), $\mathrm{kg} / \mathrm{m}^{3}$,

$\eta_{b}-$ COP of boilers,

$Q_{\text {gas }}$ - specific calorific capacity of burning of natural gas, $\mathrm{kWh} / \mathrm{m}^{3}$,

$a, b$ and $n-$ length, width and number of stories of building (for one storey building $n=1$ ),

$9 \mathrm{~m}^{2} /$ pers. - surface of building specified for one occupant [9],

$20 \mathrm{~m}^{3} / \mathrm{h}$ per person-normative hourly volume of ventilation air intended for each occupant [9],

$\rho_{\text {air }}=1.25 \mathrm{~kg} / \mathrm{m}^{3}$ - average density of air,

$C_{\text {air }}=1.005 \mathrm{~kJ} / \mathrm{kg}^{\circ} \mathrm{C}-$ specific heat of air.

Mass of water vapor $G_{l a t}, \mathrm{~kg} / \mathrm{s}$ condensed and exuded from boilers' flue gases in the gas mixing chamber is determined by the following equation:

$$
G_{\text {lat }}=G_{\text {gas }} g_{\text {cond }}=\frac{\left(\beta Q_{h d}+Q_{V}\right) \rho_{g} g_{\text {cond }}}{3600 \eta_{b} Q_{\text {gas }}}
$$

where:

$G_{\text {gas. }}$ - mass of natural gas burnt in boilers, $\mathrm{kg} / \mathrm{s}$,

$\rho_{g}=0,717 \mathrm{~kg} / \mathrm{m}^{3}-$ average density of natural gas, $g_{\text {cond }}=2.25 \mathrm{~kg} / \mathrm{kg}$ - mass of water vapor or condensate, exuded from flue gas which is produced from burning of one $\mathrm{kg}$ of natural gas [8].

Mass of whole ventilation air $G_{V}, \mathrm{~kg} / \mathrm{s}$, completely extracted from the building and introduced into the gas mixing chamber is determined by the following equation:

$$
G_{V}=\frac{a b n}{9} \frac{20 \cdot \rho_{\text {air }}}{3600}
$$

Mass of outside air $G_{s o l}, \mathrm{~kg} / \mathrm{s}$ heated up to a required temperature $t_{\text {sol }}$ in solar air heater is determined if necessary.

So, total mass of warm gases in the gas mixing chamber $G_{m i x}, \mathrm{~kg} / \mathrm{s}$ makes the following sum:

$$
\begin{aligned}
& G_{m i x}=12 \rho_{s m} \frac{\beta Q_{h d}+Q_{V}}{3600 \eta_{b} Q_{\text {gas }}}+\frac{a b n}{9} \frac{20 \cdot \rho_{\text {air }}}{3600}+ \\
& +\frac{\beta Q_{h d}+Q_{V}}{3600 \eta_{b} Q_{\text {gas }}} \rho_{g} g_{\text {cond }}+G_{\text {sol }}
\end{aligned}
$$

\section{Determination of Thermal Potentials of Gases in the Gas Mixing Chamber}

Each of gases entering in gas mixing chamber has its own thermal potential $Q_{p o t}, \mathrm{~kW}$ that can be evaluated by the following production:

$$
Q_{\text {pot }}=G C t
$$

Accordingly:

1) Thermal potential $Q_{\text {sm.pot }}, \mathrm{kW}$ of flue gases (smock), delivered from heating and separate boilers is determined by the following equation:

$$
Q_{s m . p o t}=12 \rho_{s m} \frac{\left(\beta Q_{h d}+Q_{V}\right) C_{s m} t_{s m}}{3600 \eta_{b} Q_{g a s}}
$$

where:

$C_{s m}$ - specific heat of flue gas, $\mathrm{kJ} / \mathrm{kg}^{\circ} \mathrm{C}$,

$t_{s m}$ - temperature of flue gases of boilers, determined by the following formula [8]:

$$
t_{s m}=\left(0.9707-\eta_{b}\right) / 0.00045
$$

where:

$\eta_{b}=0.85-$ COP of boilers.

Thermal potential $Q_{\text {lat.pot }}, \mathrm{kW}$ of water vapor or condensate exuded from flue gas can be evaluated by the following equation:

$$
Q_{\text {lat.pot }}=G_{\text {gas }} g_{\text {cond }} q_{\text {lat }}=\frac{\left(\beta Q_{h d}+Q_{V}\right) \rho_{g} g_{\text {cond }} q_{\text {lat }}}{3600 \eta_{b} Q_{\text {gas }}}
$$

where:

$q_{\text {lat }}=2466.2 \mathrm{~kJ} / \mathrm{kg}$ - latent heat of $1 \mathrm{~kg}$ of water vapor.

Thermal potential of ventilation air $Q_{\text {V.pot }}, \mathrm{kW}$ extracted from the building and introduced into gas mixing chamber is 
determined by the following equation:

$$
Q_{V . p o t}=G_{a i r} C_{a i r} t_{i n}=\frac{a b n 20 \cdot \rho_{a i r} C_{a i r} t_{i n}}{9 \cdot 3600}
$$

where:

$t_{i n}=18 \div 20^{\circ} \mathrm{C}-$ temperature of internal air of building in winter time.

For complete evaporation of liquid refrigerant in the evaporator of heat pump, the following thermal balance must be established in the gas-mixing chamber:

$$
Q_{o} \geq Q_{\text {o.cycl }}
$$

where:

$Q_{0 . c y c l}$ - required cooling capacity, determined by the thermodynamic cycle of heat pump, $\mathrm{kW}$.

For determining the quantity of heat (cooling capacity), required for complete evaporation of liquid refrigerant in the evaporator of heat pump, its thermodynamic cycle has to be plotted on the $i$ - $\log P$ diagram of refrigerant (for instance R-22) [5] which, is shown in Fig.3.

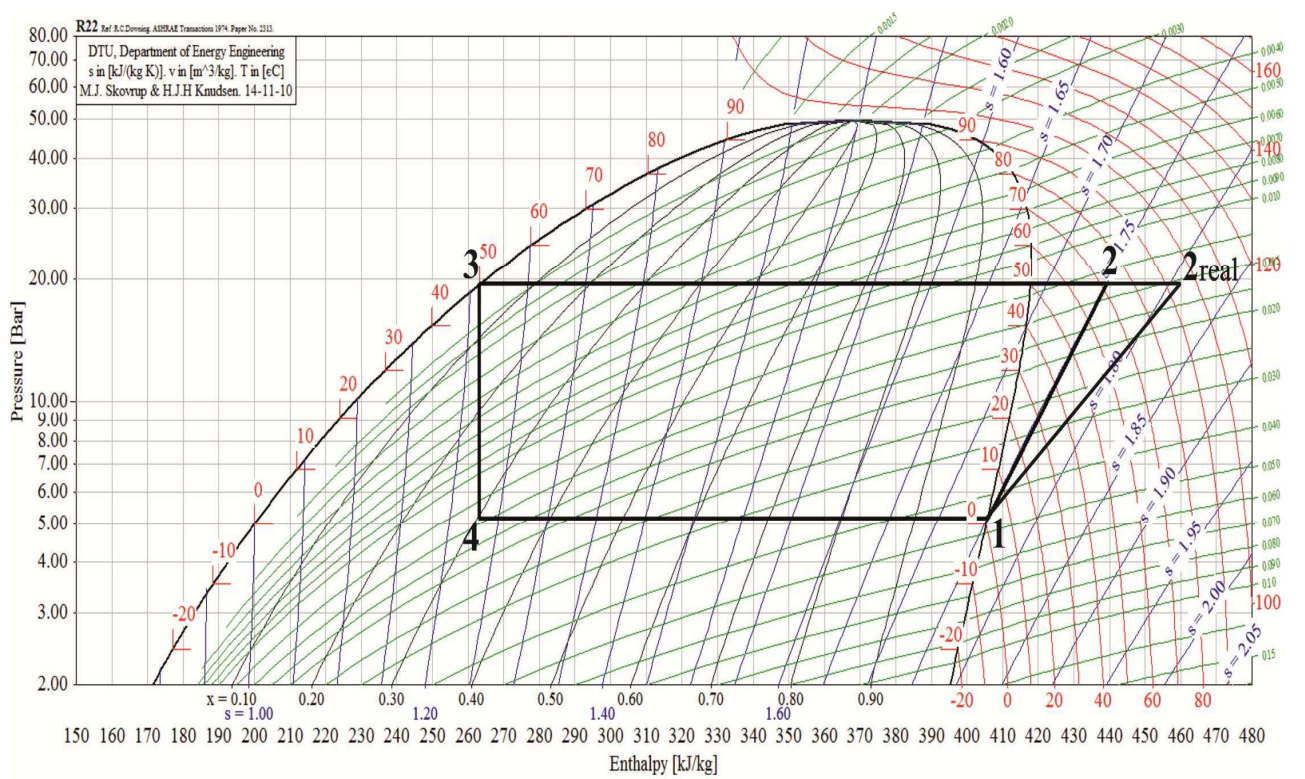

"1-2"- compression process of $R-22$ gas in the compressor, "1-2 real"- compression real process of $R$-22 gas in the compressor, " $2-3$ "- process of condensation of compressed gas in condenser of heat pump, "3-4"- process of liquid flow expansion (throttling), "4-1"-process of evaporation of liquid refrigerant in evaporator, $i_{1}, i_{2}, i_{2 . r e a l}, i_{3}, i_{4}$-enthalpies of link points of heat pump cycle.

Figure 3. Thermodynamic cycle of heat pump on the diagram " $i-\log P$ ” of refrigerant " $R-22$ "

The cycle is plotted in the range of evaporation temperature $t_{0}=1{ }^{\circ} \mathrm{C}$ and acceptable condensation temperature $t_{\text {cond }}=50^{\circ} \mathrm{C}$.

By the help of the cycle mane characteristics of heat pump, like condensation heat $Q_{\text {cond }}, \mathrm{kW}$, quantity of required heat $Q_{\text {o.cycl }}, \mathrm{kW}$, capacity of the compressor $N, \mathrm{~kW}$ and the real value of transformation rate of the heat pump $\mu$ are determined. For mentioned purposes, first the required flow rate $G_{a g . r e a l}$, $\mathrm{kg} / \mathrm{s}$ of $R-22$ in the cycle should be determined, using the following formula:

$$
G_{\text {ag.real }}=\frac{(1-\beta) Q_{h d}}{\left(i_{2 . \text { real }}-i_{3}\right)}
$$

Taking into account that the heating demand of family house makes $Q_{h d}=8.12 \mathrm{~kW}$, calculated by the method represented in $[1,2]$ and condensation heat of $1 \mathrm{~kg}$ of gas refrigerant makes $\left(i_{2 \text {.real }} i_{3}\right)=197 \mathrm{~kJ} / \mathrm{kg}$ (taken from heat pump cycle) the required flow rate of refrigerant R-22 makes:

$$
G_{\text {ag.real }}=\frac{0.6 \cdot 8.12}{197}=0.0247 \mathrm{~kg} / \mathrm{s} .
$$

Quantity of heat (cold) $Q_{0 . c y c l}, \mathrm{~kW}$ required by heat pump cycle is:

$$
Q_{0 . c y c l}=G_{\text {ag.real }}\left(i_{1}-i_{4}\right)=0.0247 \cdot 142.2=3.51 \mathrm{~kW}
$$

where:

$q_{0}=i_{1}-i_{4}=142.2 \mathrm{~kJ} / \mathrm{kg}$ - specific heat of evaporation of $1 \mathrm{~kg}$ of liquid refrigerant, taken from the heat pump cycle.

Quantity of condensation heat $Q_{\text {cond }}, \mathrm{kW}$ is determined as follows:

$$
Q_{\text {cond }}=G_{\text {ag.real }}\left(i_{2 . \text { real }}-i_{3}\right)=0.0247 \cdot 197=4.87 \mathrm{~kW}
$$

Capacity of the compressor $N_{\text {HP.real }}, \mathrm{kW}$ of heat pump is determined by the formula as follows:

$$
N_{H P . r e a l}=G_{\text {ag.real }}\left(i_{2 . \text { real }}-i_{1}\right)=0.0247 \cdot 54.92=1.357 \mathrm{~kW}
$$

where:

$i_{2}-i_{l}=54.92 \mathrm{~kJ} / \mathrm{kg}-$ work for compression of $1 \mathrm{~kg}$ of gas refrigerant, taken from heat pump's cycle:

Real value of transformation rate of the heat pump $\mu_{\text {real }}$ is determined by the following ratio: 


$$
\mu_{\text {real }}=\frac{Q_{\text {cond }}}{N_{H P . \text { real }}}=\frac{4.872}{1.357}=3.59
$$

In the above formulas quantities $i_{1}, i_{2 . \text { real }}, i_{3}, i_{4}, \mathrm{~kJ} / \mathrm{kg}$ are enthalpies of link points of the heat pump cycle.

So, the investigation of the heat pump cycle shows that total heat potential $Q_{0}, \mathrm{~kW}$ of the prepared gas mixture should be at least $Q_{\text {o.cycl }}=3.51 \mathrm{~kW}$ (see formula 17) for transferring enough heat to the liquid refrigerant for its complete evaporation. To checking availability of mentioned condition, the gas mixture's total heat potential should be revealed. For this purpose by the help of a mathematical model composed based on obtained above formulas, computer aided calculations were accomplished for determining masses of waste warm gases and their heat potentials in the mixing chamber. The results of calculations are given in the table 1 .

Table 1. Characteristics of waste warm gases in mixing chamber.

\begin{tabular}{|c|c|c|c|c|c|}
\hline & Smock & Ventilation inside air & $\begin{array}{l}\text { Water vapor con- } \\
\text { densate }\end{array}$ & $\begin{array}{l}\text { Warm air from solar } \\
\text { heater }\end{array}$ & $\begin{array}{l}\text { Total values in gas } \\
\text { mixture }\end{array}$ \\
\hline Masses, kg/s & 0.002 & 0.107 & 0.0004 & 0.0 & $0.1094 \approx 0.11$ \\
\hline Aver. specific heat, $\mathrm{kJ} / \mathrm{kg}^{\circ} \mathrm{C}$ & 1.11 & 1.005 & - & & 1.1 \\
\hline Temperature, $\mathrm{t}^{\circ} \mathrm{C}$ & 268 & 18 & 268 & & 29.35 \\
\hline Heat Potential, kW & 0.59 & 1.946 & 1.014 & 0.0 & $\Sigma Q_{p o t}=3.55$ \\
\hline
\end{tabular}

From the table. 1 can be seen that total heat potential of gas mixture in examined case makes $\Sigma Q_{p o t}=3.55 \mathrm{~kW}$. By the help of the exhaust fan of mixing chamber the warm gas mixture passes through the evaporator and transfers a $Q_{0}, \mathrm{~kW}$ quantity of heat to liquid refrigerant. As a result the gas mixture can be cooled from initial temperature $t_{m i x .1}=29.35^{\circ} \mathrm{C}$ up to a final temperature $t_{m i x .2}$. To avoiding freezing of surface of evaporator the limit temperature of gas mixture in the cold section of gas mixture chamber should be kept at least $t_{m i x .2}=$ $4^{\circ} \mathrm{C}$. Therefore, the quantity of heat that is transferred to the liquid refrigerant in the evaporator makes:

$$
\begin{aligned}
& Q_{o}=G_{m i x} \cdot C_{m i x}\left(t_{m i x .1}-t_{m i x .2}\right)= \\
& =0,11 \cdot 1.1(29.35-4)=3.067 \mathrm{~kW}
\end{aligned}
$$

where:

$t_{m i x .}=29.35^{\circ} \mathrm{C}-$ initial temperature of gas mixture in the warm section of mixing chamber (see tab.1),

$t_{\text {mix. } 2}=4{ }^{\circ} \mathrm{C}-$ selected limit temperature of gas mixture in the cold section of gas mixing chamber,

$C_{m i x}=1.1 \mathrm{~kJ} / \mathrm{kg}^{\circ} \mathrm{C}$ - average specific heat of gas mixture.

Quantity of heat $Q_{o}=3.067 \mathrm{~kW}$ should have been equal to the real cooling capacity $Q_{\text {o.cycl }}=3.51 \mathrm{~kW}$, required by heat pump cycle. However, it is less in $\Delta Q_{o}=3.51-3.067=0.443 \mathrm{~kW}$. For normal performance of heat pump the condition $Q_{0}=Q_{0 . c y c l}$ must be provided. The revealed inequality is resulted by nonconformity of gas mixture's real mass $G_{m i x}$ collected in mixing chamber, and required by the heat pump cycle total mass $G_{\text {mix.req. }}$ The required total mass $G_{\text {mix.req }}, \mathrm{kg} / \mathrm{s}$ of gas mixture should be determined by the following equation:

$$
G_{\text {mix.req }}=\frac{Q_{\text {o.cycl }}}{C_{\text {mix }}\left(t_{m i x .1}-t_{m i x .2}\right)}=\frac{3.51}{1.1 \cdot(29.35-4)}=0.126 \mathrm{~kg} / \mathrm{s}
$$

While in reality the mass of gas mixture makes only $0.11 \mathrm{~kg} / \mathrm{s}$ as table 1 shows that. So, the missing mass of gas mixture in the mixing chamber makes: $\Delta G_{\text {mix.miss }}=$ $0.126-0.11=0.016 \mathrm{~kg} / \mathrm{s}$. One of the easiest ways to complete the required mass $G_{m i x . r e q}, \mathrm{~kg} / \mathrm{s}$ of gas mixture is the application of a solar air heater for heating outside air in quantity of $\Delta G_{\text {mix.miss }}=0.016 \mathrm{~kg} / \mathrm{s}$ from temperature $t_{\text {out }}$ up to temperature $t_{\text {airfin }}=30^{\circ} \mathrm{C}$ for supplying it to the gas mixing chamber and completing the required mass of the mixture.

For preparing and supplying $\Delta G_{\text {mix.miss }}=0.016 \mathrm{~kg} / \mathrm{s}$ of warmed air, lately developed "Shell and tub type solar water heater" [3] is chosen, which is able to perform as solar air heater too. Assuming that the missed quantity of gas mixture mass $\Delta G_{\text {mix.miss }}=0.016 \mathrm{~kg} / \mathrm{s}$ is distributed by 10 parallel installed units of solar air heater, the quantity of air flow rate in each unit will make $g_{\text {air }}=G_{\text {mix.miss }} / 10=0.0016 \mathrm{~kg} / \mathrm{s}$. To determining the total length $l_{\text {sol }}$, $\mathrm{m}$ of the solar air heater, the following equation was derived:

$$
l_{\text {sol }}=\frac{2 A g_{\text {air }} C_{\text {air }}\left(t_{\text {air.fin }}-t_{\text {out }}\right)}{996,7 \cdot A \cdot d_{\text {ext.met.tub }}+\pi\left(t_{\text {out }}-t_{\text {air.fin }}\right)}
$$

where:

$A=13.77 \mathrm{~m}^{\circ} \mathrm{C} / \mathrm{W}$ resistance to heat lost from cylindrical solar air heater,

$g_{\text {air }}=0.0016 \mathrm{~kg} / \mathrm{s}-$ quantity of air flowing through each unit of solar heater with length $l_{\text {sol }}$,

$C_{\text {air }}=1005 \mathrm{~J} / \mathrm{kg}^{\circ} \mathrm{C}-$ specific heat of air,

$t_{\text {air.fin }}=30^{\circ} \mathrm{C}$-required final temperature of air at the outlet of solar air heater,

$t_{\text {out }}=-19^{\circ} \mathrm{C}-$ outside air temperature (for instance in Yerevan, Armenia),

$d_{\text {ext.met.tub }}=0.021 \mathrm{~m}-$ external diameter of air heating metal tub of cylindrical solar air heater.

Substitution above data for values given in (23) will obtain the lengths $l_{\text {sol }}=16.15 \mathrm{~m}$ of each of 10 parallel solar heaters. The solar air heater is made in form of modules. Each module consists of $l_{\text {unit }}=1.2 \mathrm{~m}$ long, parallel installed 10 units. Therefore, the total length of all 10 units in a module makes $12 \mathrm{~m}$. Through each unit flows outside air with initial temperature $t_{\text {out }}=-19^{\circ} \mathrm{C}$ and is supplied to gas mixing chamber with final temperature $t_{\text {air } f i n}=30^{\circ} \mathrm{C}$. The modules of solar units are connected each to other in series as was shown in Fig.1. The following ratio defines the number of modules $n_{s . h}$, connected in series:

$$
n_{s . h}=\frac{l_{\text {sol }}}{l_{\text {unit }}}, \text { or } n_{s . h}=\frac{16.15}{1.2}=14 \text { modules }
$$

The other main equipment's characteristics to be determined for daytime sunshine period of the heating season, 
when $\beta=0.4$ are thermal power of the heating boiler- $Q_{b}=\beta Q_{h d}$ or $Q_{b}=0.4 \cdot 8.12=3.25 \mathrm{~kW}$; temperature $t_{w .2}$ of heating water at the outlet of the boiler $t_{w .2}=\frac{t_{w . \text { int }}-\beta t_{w .1}}{(1-\beta)}$, or $t_{w .2}=\frac{45-0.4 \cdot 30}{(1-0.4)}=55^{\circ} \mathrm{C}$; thermal power of the heat pump: $\quad Q_{H P}=(1-\beta) Q_{h d} \quad$ or $\quad Q_{H P}=0.6 \cdot 8.11=4.88 \mathrm{~kW}$; number of modules of solar air heater, connected in series is 14.0; flow rate of heating water $G_{w}, \mathrm{~kg} / \mathrm{s}$ circulating in the whole hybrid system is determined:

$$
G_{w}=\frac{Q_{h d}}{c_{w}\left(t_{w .2}-t_{w .1}\right)}, \text { or } G_{w}=\frac{8.12}{4.18(55-30)}=0.0777 \mathrm{~kg} / \mathrm{s}
$$

Based on listed above characteristics the hybrid system's design can be accomplished.

\section{Operation and Calculation of Hybrid System in Cloudy Daytime or Nighttime Period of Heating Season}

In cloudy daytime or nighttime period of heating season because of absence of solar radiation the solar air heater does not participate at formation of gas mixture. It is clear that in this regime the thermal potential of gas mixture in gas mixing chamber will be significantly less than in sunshine period regime. To avoiding mentioned disadvantage the rate of heating demand portion on the boiler is increased from $\beta=0.4$ up to $\beta=0.6$. Increasing of $\beta$ from 0.4 to 0.6 brings to grow of required temperature of heating water up to $t_{w .2}=67.5^{\circ} \mathrm{C}$. In this case the rate of circulation of heating water in whole hybrid system becomes $G_{w}=0.052 \mathrm{~kg} / \mathrm{s}$. Thermal power of the boiler changes to $Q_{b}=4.87 \mathrm{~kW}$ and power of the heat pump becomes $Q_{H P}=3.25 \mathrm{~kW}$. The characteristics of waste warm gases in mixing chamber in case of $\beta=0.6$ are represented in the table 2 .

Table 2. Characteristics of waste warm gases in mixing chamber in case of $\beta=0.6$.

\begin{tabular}{llllll}
\hline & Smock & Ventilation inside air & Water vapor condensate & $\begin{array}{l}\text { Warm air from solar } \\
\text { heater }\end{array}$ & $\begin{array}{l}\text { Total values in gas } \\
\text { mixture }\end{array}$ \\
\hline Masses, $\mathrm{kg} / \mathrm{s}$ & 0.0024 & 0.107 & 0.0005 & 0.0 & 0.1104 \\
Aver. specific heat, $\mathrm{kJ} / \mathrm{kg}^{\circ} \mathrm{C}$ & 1.11 & 1.005 & - & & 1.1 \\
Temperature, $\mathrm{t}^{\circ} \mathrm{C}$ & 268 & 18 & 268 & & 32.2 \\
Heat Potential, $\mathrm{kW}$ & 0.724 & 1.946 & 1.24 & 0.0 & $5 Q_{\text {pot. }}=3.91$ \\
\hline
\end{tabular}

Because of increasing of total heat potential of gas mixture compared to the regime with $\beta=0.4$, in case of $\beta=0.6$ regime the quantity of heat which is transferred to the liquid refrigerant in the evaporator located in gas mixing chamber becomes higher:

$$
Q_{o}=0.11049 \cdot 1.1 \cdot(32.2-4)=3.42 \mathrm{~kW}
$$

The further calculation of the system should be accomplished by the method similarly to former sunshine period regime. Calculation showed that in $\beta=0.6$ regime the complete heating of the building without additional help of solar air heater is possible and the system can perform sufficiently. Therefore, the system needs automation equipment for switching on the valve of air duct connecting solar air heater with gas mixing chamber in sunshine period. In cloudy or nighttime period the automation equipment switches the solar heater valve off.

\section{Operation and Calculation of Hybrid System in Summertime Cooling Season}

In summertime cooling season the system operates for cooling the building. For this purpose, the heat pump operates in reveres mode and becomes a refrigerator. In this regime, the heating boiler and solar air heater switched off. Into gas mixing chamber enters only outside air for cooling condenser (wintertime evaporator) of heat pump which prepares cold water and supplies into fan - coils of the building. The cold water in fan-coils absorbs excessive heat of inside space and cools it. Because of absorption of heat, the water in fan-coils is warmed up to a temperature $t_{\text {w.ret.f-c }}$ which can be determined by the following formula:

$$
t_{w . r e t . f-c}=t_{c . w}+\frac{Q_{c d}}{G_{w} C_{w}}
$$

where:

$t_{w . \text { ret.f-c }}$ - temperature of return water from fan-coils to evaporator of heat pump, ${ }^{\circ} \mathrm{C}$,

$t_{c . w}=10^{\circ} \mathrm{C}$ - temperature of cold water supplied from evaporator into fan-coils,

$Q_{c d}$ - cooling demand of examined building determined by the method published in [7], makes $6.54 \mathrm{~kW}$.

$G_{w}$ - cooling water flow rate, circulating in cooling system of building, $\mathrm{kg} / \mathrm{s}$,

$C_{w}=4.18-$ specific heat of water, $\mathrm{kJ} / \mathrm{kg}^{\circ} \mathrm{C}$.

To provide an acceptable temperature of the cooling water at the outlet of fan-coils the water flow rate $G_{w}$ by the help of variable speed pump must be increased from wintertime $G_{\text {w.wint }}=0.052 \div 0.0777 \mathrm{~kg} / \mathrm{s}$ up to $G_{\text {w.sum. }}=0.15 \mathrm{~kg} / \mathrm{s}$. In this case, the temperature of warmed in fan-coils return water makes:

$$
t_{\text {w.ret.f }-c}=10+\frac{6.54}{0.15 \cdot 4.18}=10+10.4=20.4{ }^{\circ} \mathrm{C} .
$$

The cooling power of heat pump is equal to the cooling demand of the building. Inside air at the temperature $t_{\text {in.sum }}=25^{\circ} \mathrm{C}$ enters into fan coils, where transfers excessive heat to the cooling water, supplied from the evaporator of heat pump. Warmed water returns from fan-coils to the evaporator 
of heat pump where is cooled from $t_{w . r e t . f-c}=20.4^{\circ} \mathrm{C}$ to the temperature $t_{c . w}=10^{\circ} \mathrm{C}$. Afterwards cooled water is supplied back to fan-coils. Therefore, the cooling power of the heat pump can be determined as follows:

$$
\begin{gathered}
Q_{H P}=G_{w} c_{w}\left(t_{w . r e t . f-c}-t_{c . w}\right) \text { or } \\
Q_{H P}=0.15 \cdot 4.18(20.4-10)=6.53 \mathrm{~kW}
\end{gathered}
$$

In fan-coils the cooling water absorbs heat from inside air at comfortable temperature $t_{\text {in.sum }}=25^{\circ} \mathrm{C}$, cools it to temperature $t_{\text {airsup. }}=18{ }^{\circ} \mathrm{C}$ and blows it back to inside space for keeping temperature $t_{\text {in.sum }}=25^{\circ} \mathrm{C}$. Circulation of cooling water takes place by the help of the same variable speed pump, which serves in wintertime too.

In summer time outside air enters into gas mixing chamber by the help of exhaust fan of the chamber and cools the condenser. Condensation temperature of the refrigerant $t_{\text {cond.sum }}$ is selected in 5 to $7{ }^{\circ} \mathrm{C}$ higher, than the condenser cooling summertime outside air temperature $t_{\text {out.sum }}$.

\section{Energy Efficiency and Cost Effectiveness of Heating and Cooling Hybrid System}

To reveal energy efficiency and cost effectiveness of the "Hybrid" system, it is necessary to develop its optimization mathematical model. The mathematical model represents the set of totality of all equations forming the methods for determination of design, constructive, energy and economic parameters of the "Hybrid" system, which are included into the economical functional of the system. The economical functional is the criteria of energy efficiency and cost effectiveness of the system. For determining the value of economical functional $T_{s}, \$ / \mathrm{m}^{2}$ year, the following ratio is used:

$$
T_{s}=\frac{T}{S}
$$

where:

$T$ - annual total expenditures for assembling and operating of "Hybrid" system, \$/year,

$S$ - surface of floor of served house, $\mathrm{m}^{2}$.

The required value of annual total expenditures $T$, \$/year for running of "Hybrid" system is determined by the following formula:

$$
T=\frac{\Sigma K}{Y}+\Sigma U
$$

where:

$\sum K$-total capital cost of the system, \$,

$\sum U$ - total annual operational cost of the system, \$/year,

$Y$-capital investments payback period, which is selected equal to the life cycle duration of the system or any other period in case of which the cost of heating and cooling $T_{s}$, $\$ / \mathrm{m}^{2}$ year becomes affordable for consumers and acceptable for investors.
The total capital cost $\sum K, \$$ is a function of constructive and energy characteristics of main equipment. For the "Hybrid" system total capital cost $\sum K, \$$ is determined by the following sum:

$$
\Sigma K=\left(\begin{array}{l}
K_{b}+K_{\text {sep.b }}+K_{H E X . V}+K_{H P}+K_{\text {cond.(evap) }}+ \\
+K_{\text {sol.heat }}+K_{\text {mix.chamb }}+K_{\text {fan-coil }}+K_{\text {aut.syst }}
\end{array}\right) \cdot 1.4
$$

where:

$K_{b}$ - cost of heating boiler, $\$$,

$K_{\text {sep.b. }}$ - cost of separate heating boiler, installed for heating ventilation fresh air to replace exhaust air from the building, $\$$, $\$$,

$K_{H E X . V}-$ cost of ventilation fresh air heating heat exchanger,

$K_{H P}-$ cost of heat pump, $\$$,

$K_{\text {cond.(evap) }}-$ cost of winter condenser for intermediate worming of heating water (summer evaporator), $\$$,

$K_{\text {sol.heat }}$ - cost of air solar heater, \$,

$K_{\text {mix.chamb }}-$ cost of gas mixing chamber, $\$$,

$K_{\text {fan-coil }}$ - total cost of fan-coils installed in the building, \$,

$K_{\text {aut.syst }}-$ cost of automatic control system, \$,

1.4-system assembling, testing and extra expenditures factor.

The costs of listed equipment are determined below for cloudy and nighttime $\beta=0.6$ regime

Cost of heating boiler, $K_{b}, \$$ is determined by its thermal power $\beta Q_{h d}$ by the following production:

$$
K_{b}=C_{b} \cdot \beta Q_{h d}
$$

where:

$C_{b}=80 \$ / \mathrm{kW}-$ specific cost of boiler.

Then the cost of boiler in case of $\beta=0.6$ makes:

$$
K_{b}=80 \cdot 0.6 \cdot 8.12=\$ 390
$$

Cost of separate boiler, $K_{\text {sep.b }}$, $\$$ is determined by its thermal power $Q_{\text {sep.b. }}, \mathrm{kW}$ as follows:

$$
K_{\text {sep.b }}=C_{b} Q_{\text {sep.b }},
$$

where:

$$
Q_{\text {sep.b }}=\frac{a b n \cdot 20 \cdot \rho_{\text {air }} C_{\text {air }}\left(t_{\text {in }}-t_{\text {out }}\right)}{9 \cdot 3600}=4.0 \mathrm{~kW}
$$

and

$$
K_{\text {sep.b }}=80 \$ / \mathrm{kW} \cdot 4.0 \mathrm{~kW}=\$ 320
$$

Cost of ventilation fresh air heat exchanger connected to separate heating boiler, $\mathrm{K}_{\mathrm{HEX} . \mathrm{V}}, \$$ is the following production:

$$
K_{H E X . V}=C_{H E} F_{H E X . V}
$$

where:

$C_{H E}=20 \$ / \mathrm{m}^{2}-$ specific cost of water to air heat exchanger,

$F_{H E X . V}$ - heat exchange surface of "water to air" type heat exchanger, which is determined by the following ratio: 


$$
F_{H E X . V}=\frac{Q_{V}}{k_{H E} \Delta t}
$$

where:

$Q_{V}=4 \mathrm{~kW}$ - quantity of heat for heating the ventilation fresh air from outside temperature $t_{\text {out }}=-19^{\circ} \mathrm{C}$ to the inside temperature $t_{i n}=+18^{\circ} \mathrm{C}$,

$k_{H E}=35 \mathrm{~W} / \mathrm{m}^{2 \circ} \mathrm{C}-$ heat transfer coefficient of water to air type heat exchanger,

$\Delta t$ - mean logarithmic temperature difference in counter flow heat exchanger, which is determined by the following equation:

$$
\Delta t=\frac{\left(t_{w . \text { sup }}-t_{\text {in }}\right)-\left(t_{w . \text { ret }}-t_{\text {air.out }}\right)}{\ln \frac{t_{w . \text { sup }}-t_{\text {in }}}{\left(t_{w . \text { ret }}-t_{\text {air.out }}\right)}}
$$

Substitution of quantities in the equation for their real values gives the following value of mean temperature difference: $\Delta t=\frac{(70-18)-((15-19))}{\frac{(70-18)}{(15-19)}}=42.4^{\mathrm{o}} \mathrm{C}$, in case of which heat exchange surface makes $F_{H E X . V}=\frac{4}{0.034 \cdot 42.4}=2.775 \mathrm{~m}^{2}$. Taking into account that specific cost of water to air heat exchanger is $C_{H E}=20 \$ / \mathrm{m}^{2}$, the cost of heat exchanger makes:

$$
K_{H E X . V}=20 \$ / \mathrm{m}^{2} \times 2,775 \mathrm{~m}^{2}=\$ 56
$$

Cost of heat pump, $K_{H P}, \$$ is the sum of costs of the compressor, condenser, evaporator and other auxiliary equipment:

$$
\mathrm{KHP}=(\mathrm{Kcomp}+\mathrm{K} \text { evap. }(\text { cond }))
$$

Cost of compressor $K_{\text {comp }}$, \$ depends on its cooling capacity and is defined by the following production:

$$
K_{\text {comp }}=C_{\text {comp }} \cdot Q_{\text {comp }}
$$

where:

$C_{\text {comp }}$ - specific cost of compressor assumed in average $C_{\text {comp }}=130 \$ / \mathrm{kW}$.

$Q_{\text {comp }}$ - cooling power of compressor (heat pump) in summer cooling regime including heat pump's cooling load $6.5 \mathrm{~kW}$ for covering building's cooling demand and $1.1 \mathrm{~kW}$ for summertime cooling of ventilation fresh air. The cost of selected compressor makes:

$$
K_{\text {comp }}=130 \$ / \mathrm{kW} \cdot(6.5+1.1) \mathrm{kW}=\$ 988 .
$$

Cost of winter evaporator (summer condenser), installed in gas mixing chamber, $\mathrm{K}_{\text {evap.(cond), }} \$$ is determined by the following production:

$$
K_{\text {evap.(cond) }}=C_{\text {evap.(cond) }} F_{\text {evap. }(\text { cond })}
$$

where:

$F_{\text {evap.(cond })}=32 \mathrm{~m}^{2}$-summer time required surface of "refrigerant-air" type evaporator ,
$C_{\text {evap.(cond })}=20 \$ / \mathrm{m}^{2}-$ specific cost of $1 \mathrm{~m}^{2}$ of "refrigerant-air" type winter evaporator.

The cost of mentioned heat exchanger makes:

$$
K_{\text {evap. (cond })}=20 \$ / \mathrm{m}^{2} \cdot 32 \mathrm{~m}^{2}=\$ 640 .
$$

So the total cost of heat pump makes:

$$
K_{H P}=(988+640)=\$ 1628 .
$$

Cost of winter condenser (summer evaporator) for intermediate worming of heating water, $\mathrm{K}_{\text {cond.(evap) }} \$$ is determined by the following production:

$$
K_{\text {cond.(evap) }}=C_{\text {cond.(evap) }} F_{\text {cond.(evap) }} \text {, }
$$

where:

$F_{\text {cond.(evap) }}=2.4 \mathrm{~m}^{2}$-summer time required surface of "refrigerant-water" type condenser,

$C_{\text {cond.(evap) }}=40 \$ / \mathrm{m}^{2}-$ specific cost of $1 \mathrm{~m}^{2}$ of "refrigerant-water" type heat exchanger, whit heat transfer coefficient $0.35 \mathrm{~kW} / \mathrm{m}^{20} \mathrm{C}$.

In these conditions, the cost of winter condenser - summer evaporator makes:

$$
K_{\text {cond.(evap) }}=40 \$ / \mathrm{m}^{2} \cdot 2.4 \mathrm{~m}^{2}=\$ 96
$$

Cost of air solar heater, $K_{\text {sol.heat. }} \$$ is determined by the following formula:

$$
K_{\text {sol.heat }}=C_{\text {unit }} n_{\text {unit }}
$$

where:

$C_{\text {unit }}=\$ 3.5$-cost of each unit of solar heater with length $1.2 \mathrm{~m}$.

$n_{\text {unit }}$ - total number of solar heater units determined by dividing of total length $l_{\text {sol }}$ of solar air heater, (see equation (23)) by the length of each unite $1.2 \mathrm{~m}$. Calculation shows that $l_{\text {sol }}=10 \times 16.1 \mathrm{~m}$ and $n_{\text {unit }}=l_{\text {sol }} / 1.2=134$. So, the cost of solar air heater is:

$$
K_{\text {sol.heat }}=3.5 \$ \text { unitx } 134 \text { units }=\$ 469
$$

Cost of gas mixing chamber, $K_{\text {mix.chamb}}$, $\$$ is determined by the following production:

$$
\mathrm{K}_{\text {mix.chamb }}=\mathrm{C}_{\text {mix.chamb }} \mathrm{V}_{\text {mix.chamb}} \text {, }
$$

where the volume of mixing chamber $V_{\text {mix.chamb }}, \mathrm{m}^{3}$ depends on the surface $F_{\text {evap.(cond) }}, \mathrm{m}^{2}$ and height $\sigma_{\text {evap }}, \mathrm{m}$ of the evaporator. According above calculations the heat exchange surface is $F_{\text {evap. } \text { (cond })}=32 \mathrm{~m}^{2}$ that occupies about $3.2 \mathrm{~m}^{2}$ horizontal surface, and the height $\sigma_{\text {evap }}$ is assumed $\sigma_{\text {evap }}=0.25 \mathrm{~m}$. Therefore, the volume of the mixing chamber can be accepted about $3.2 \mathrm{~m}^{2} \cdot 0.25 \mathrm{~m}=0.8 \mathrm{~m}^{3}$. The specific cost of $1 \mathrm{~m}^{3}$ of mixing chamber including the cost of exhaust fan, hermetic sealing and insulation is assumed $C_{\text {mix.chamb }}=90 \$ / \mathrm{m}^{3}$.

So the total cost of mixing chamber makes

$$
K_{\text {mix.chamb }}=0,8 \mathrm{~m}^{3} \mathrm{x} 90 \$ / \mathrm{m}^{3}=\$ 72 .
$$

Total cost of fan-coils installed in the building, $\mathrm{K}_{\text {fan-coil }}, \$$ is 
determined by the following production:

$$
K_{\text {fan-coil }}=C_{\text {fan-coil }} F_{\text {fan-coil }}
$$

where:

$F_{\text {fan-coil }}=6,7 \mathrm{~m}^{2}-$ total heating surface of fan-coils,

$C_{\text {fan-coil }}=40 \$ / \mathrm{m}^{2}$ - specific cost of $1 \mathrm{~m}^{2}$ of heating surface of fan-coil.

So the total cost of fan-coils makes

$$
K_{\text {fan-coil }}=40 \$ / \mathrm{m}^{2} \cdot 6.7 \mathrm{~m}^{2}=\$ 268
$$

Cost of automatic control simple system $K_{\text {aut.sust }}$ \$, operating for switching on and off at different times of the day the mixing chamber's fan is assumed $K_{\text {aut.syst }}=200 \$$.

So, the approximate total capital cost $\sum K, \$$ of the hybrid heating and cooling system is determined by the following sum:

$$
\Sigma K=\left(\begin{array}{l}
\$ 390+\$ 320+\$ 56+ \\
+\$ 1628+\$ 96+\$ 469+ \\
+\$ 72+\$ 268+\$ 200
\end{array}\right) 1.4=\$ 3499 \cdot 1.4=\$ 4899
$$

Total annual operational cost $\Sigma \mathrm{U}, \$$ /year of the hybrid system is formed from following annual costs:

$$
\Sigma U=U_{\text {gas }}+U_{\text {el.HP.wint }}+U_{\text {el.HP.summ }}+U_{\text {rep }}+U_{\text {el.fan.year }}
$$

where:

$U_{\text {gas }}$ - cost of annual consumption of gas by water heating boilers, $\$ /$ seas.,

$U_{\text {el.HP.wint }}-$ cost of electricity consumed by the heat pump in winter heating season, \$/seas.,

$U_{\text {el.HP.summ. }}$ - cost of electricity consumed by the heat pump in summer cooling season, \$/seas.,

$U_{\text {rep }}$ - annual cost of current repair of the system, \$/year,

$U_{\text {el.fan.year }}$ - annual cost of electricity consumed by the exhaust fan of mixing chamber, \$/year.

Total cost of gas consumption by the boilers, $U_{\text {gas }}$, $\$ /$ seas. is determined by the following sum:

$$
U_{\text {gas }}=C_{\text {gas }} m_{\text {h.seas }}\left(V_{\text {gas.day }} Z_{\text {seas.day }}+V_{\text {gas.night }} Z_{\text {seas.nigh }}\right)
$$

where:

$C_{\text {gas }}=0,335 \$ / \mathrm{m}^{3}$ tariff of natural gas in given area,

$m_{\text {h.seas }}=0.5$ - averaging factor of variable heating demands of the house during heating season.

$Z_{\text {seas.day }}$ - duration of daytime or sunshine period of heating season, for $\left(\beta_{\text {day }}=0.4\right)$ makes $1260 \mathrm{~h}$

$Z_{\text {seas.night }}$ - total duration of nighttime and cloudy daytime periods of heating season for $\left(\beta_{\text {night }}=0.6\right)$ makes $2240 \mathrm{~h}$.

$V_{\text {gas.day }}$ - quantity of gas, consumed at daytime sunshine period, when $\beta=0.4$,

$V_{\text {gas.night }}$ - quantity of gas consumed at nighttime and cloudy period of heating season, when $\beta=0.6$.

Quantity of gas consumed at daytime sunshine period of heating season is determined by the following equation:

$$
\begin{gathered}
V_{\text {gas.day }}=\frac{\left(\beta_{\text {day }} Q_{h d}+Q_{V}\right)}{\eta_{b} Q_{\text {gas }}} \mathrm{m}^{3} / \mathrm{h}, \text { or } \\
V_{\text {gas.day }}=\frac{(0.4 \cdot 8.12+4)}{0.85 \cdot 9.3}=0.917 \mathrm{~m}^{3} / \mathrm{h}
\end{gathered}
$$

Quantity of gas consumed at nighttime period of heating season when $\beta_{d a y}=0.6$ is determined by the following equation:

$$
\begin{gathered}
V_{\text {gas.night }}=\frac{\left(\beta_{\text {night }} Q_{h d}+Q_{V}\right)}{\eta_{b} Q_{\text {gas }}} \mathrm{m}^{3} / \mathrm{h}, \text { or } \\
V_{\text {gas.night }}=\frac{(0.6 \cdot 8.12+4)}{0.85 \cdot 9.3}=1.12 \mathrm{~m}^{3} / \mathrm{h}
\end{gathered}
$$

Seasonal total consumption of gas $V_{\text {gas.seas }}, \mathrm{m}^{3} / \mathrm{seas}$ by both boilers can be determined by the equation as follows:

$V_{\text {gas.seas }}=m_{\text {h.seas }}\left\lfloor V_{\text {gas.day }} \cdot Z_{\text {seas.day }}+V_{\text {gas.night }} \cdot Z_{\text {seas.night }}\right\rfloor$

Substitution for values of equation (41) above quantities and accomplishing calculations will obtain the following seasonal total gas consumptions $V_{\text {gas.seas }}$ by both boilers:

$$
\begin{aligned}
& V_{\text {gas.seas }}=0.5[0.917 \cdot 1260+1.12 \cdot 2240]=\mathrm{m}^{3} / \mathrm{seas} \\
& =0.5(1155.4+2509)=1832
\end{aligned}
$$

The total seasonal cost of consumed gas is the following:

$$
U_{\text {gas }}=1832 \mathrm{~m}^{3} / \text { seas } \times 0,335 \$ / \mathrm{m}^{3}=614 \$ / \text { seas. }
$$

Cost of electricity consumed by the heat pump during winter heating season, $\mathrm{U}_{\mathrm{el} . \mathrm{HP}}, \$ /$ seas. is determined by the following production:

$$
U_{e l . H P}=C_{e l} N_{H P . w i n t . s e a s}
$$

where:

$C_{e l}$-tariff of electricity in given area, assumed $0.08 \$ / \mathrm{kWh}$,

$N_{H \text { P.wint.seas }}$ - winter seasonal consumption of electricity by the heat pump, kWh.

Winter seasonal consumption of electricity by the heat pump is determined by the sum of nighttime $\left(\beta_{\text {night }}=0.6\right)$ and daytime $\left(\beta_{d a y}=0.4\right)$ periods by the help of the following formula:

$$
\begin{aligned}
& N_{H P . w i n t . s e a s}= \\
& =\frac{Q_{h d} m_{h . s}\left(\left(1-\beta_{\text {night }}\right) Z_{\text {seas.night }}+\left(1-\beta_{\text {day }}\right) Z_{\text {seas.day }}\right)}{\mu_{\text {real }}}
\end{aligned}
$$

where heat pump transformation coefficient $\mu_{\text {real }}$ according to formula (20) equals to 3.59 .

Therefore, winter seasonal consumption of electricity by the heat pump makes:

$$
\begin{aligned}
& N_{\text {HP.wint } . \text { seas }}=\frac{8.12 \cdot 0.5((1-0.6) 2240+(1-0.4) 1260)}{3.59}= \\
& =\frac{6707.12}{3.59}=1868 \mathrm{kWh} / \mathrm{seas}
\end{aligned}
$$


The summertime consumption of electricity by the heat pump working as a refrigerator for cooling the building and ventilation fresh air $N_{\text {el.cooling.summ }}, \mathrm{kW} / \mathrm{seas}$ is determined by the formula as follows:

$$
N_{\text {el.cooling.summ }}=\frac{\left(Q_{c d}+Q_{\text {vent.summ }}\right) Z_{c . \text { seas }} m_{\text {c.seas }}}{\varepsilon}
$$

where:

$Q_{c d}=6.54 \mathrm{~kW}-$ design value of cooling demand of the house [7], $\mathrm{kW}$,

$Q_{\text {vent.summ }}=1.1 \mathrm{~kW}$ - cooling demand for cooling ventilation fresh air, in summer season, when temperature difference between outside and inside air temperatures is $\left(t_{\text {out }}-t_{\text {in }}\right)=35^{\circ} \mathrm{C}-25^{\circ} \mathrm{C}=10^{\circ} \mathrm{C}$.

$Z_{c \text { seas }}=1500 \mathrm{~h}-$ duration of summer cooling season,

$m_{\text {c.seas }}=0.5-$ averaging factor of variable cooling demands of the house during cooling season.

$\varepsilon=2.9-$ COP or efficiency of the heat pump, operating in refrigerating mode.

Substitution above values for formula (44) the following summertime seasonal consumption of electricity by the heat pump is obtained:

$$
N_{\text {el.cooling.summ }}=\frac{(6.54+1.1) \cdot 1500 \cdot 0.5}{2.9}=1976 \mathrm{kWh}
$$

So, total annual consumption of electricity by the heat pump makes $N_{\text {HP.ann. }}=1868+1976=3844 \mathrm{kWh}$

Annual cost of consumed electricity by the heat pump $U_{\text {el.HP }}$, \$/year is:

$$
U_{e l . H P}=0.08 \$ / \mathrm{kWh} \cdot 3844 \mathrm{kWh}=308 \$ / \text { year }
$$

Annual cost of current repair of the system $U_{\text {rep }}$, \$/year is determined by the following formula:

$$
U_{\text {rep }}=0.04 \Sigma K=0.04 \cdot 4899=196 \$ / \text { year }
$$

Summarizing obtained data for annual operational cost will get the following results:

Annual cost of consumed gas makes - 614.6 \$/year, annual cost of consumed electricity - 308 \$/year. Total annual operational cost is $\Sigma U=614.6+308+196=1119$ \$/year.

Annual expenditures for running the hybrid system makes:

$$
T=\frac{4899}{25}+1119=196+1119=1315 \$ / \text { year } .
$$

Respectively the cost of annual heating and cooling referred to $1 \mathrm{~m}^{2}$ of building makes:

$$
T_{S}=1315 / 144=9.13 \$ / \mathrm{m}^{2} \text { year }
$$

For evaluating energy efficiency of developed heating and cooling hybrid system it is compared with ordinary heating and cooling simple system consisted of heating boiler, ventilation outside fresh air preheating boiler with air heating exchanger, fan-coils, heating water circulation pumps, air conditioners for summertime cooling and simple automation system. The winter heating demand $Q_{h d}, \mathrm{~kW}$ and summer cooling demand $Q_{c d}, \mathrm{~kW}$ for hybrid and ordinary systems are the same. Capital cost of ordinary system is the following sum:

$\Sigma K_{\text {ord }}=\left(K_{b}+K_{\text {sep.b }}+K_{H E X . V}+K_{A C}+K_{\text {fan-coil }}+K_{\text {aut.syst }}\right) \cdot 1.4$

where $K_{b}=80 \cdot 8.12=\$ 650 ; K_{\text {sep. } b}=\$ 320 ; K_{H E X . V}=\$ 56$;

$K_{A C}=400 \$ / \mathrm{kW}$ x $(6.54+1.1) \mathrm{kW}=\$ 3056 ; K_{\text {fan-coil }}=\$ 268$;

$K_{\text {aut.syst }}=\$ 200$.

The total capital cost of ordinary system makes:

$$
\Sigma K_{\text {ord }}=4550 \cdot 1.4=\$ 6370
$$

Comparison shows that the capital cost of hybrid system in $6370-4899=\$ 1471$ is less. Therefore, the developed hybrid system in $23 \%$ is more cost effective.

Annual operational cost of ordinary heating and cooling system

Ordinary system's gas consumption for winter heating makes:

$$
\begin{aligned}
& B_{\text {gas.seas.ord.heat. }}= \\
& =\frac{Q_{h d} m_{h . \text { seas }} Z_{\text {heat.seas }}}{\eta_{b} Q_{\text {gas }}}=\frac{8.12 \cdot 0.5 \cdot 3500}{0.85 \cdot 9.3}=1798 \mathrm{~m}^{3} / \text { seas }
\end{aligned}
$$

where:

$Z_{\text {heat.seas. }}=3500 \mathrm{~h}-$ total duration of heating season.

Seasonal gas consumption in the separate boiler $V_{\text {gas.vent }}$, $\mathrm{m}^{3} /$ seas., for preparing warm air for ventilation purposes makes: $B_{\text {gas.ord.vent. }}=914 \mathrm{~m}^{3} / \mathrm{seas}$. So, total gas consumption for heating and ventilation in ordinary heating and cooling system makes $\Sigma B_{\text {gas. seas.ord.heat }}=1798+914=2712 \mathrm{~m}^{3} /$ seas, while the hybrid system consumes $1834,7 \mathrm{~m}^{3} / \mathrm{seas}$ of natural gas. So, gas saving by hybrid system compared to ordinary system makes: $2712-1834.7=877.3 \mathrm{~m}^{3} /$ seas or $32.3 \%$.

Electricity consumption by air conditioners of ordinary system $N_{\text {sum.aircond, }} \mathrm{kWh} / \mathrm{seas}$ for summer cooling and ventilation is calculated by the following formula:

$$
N_{\text {sum.air.cond }}=\frac{\left(Q_{c d}+Q_{V . s u m}\right) \cdot m_{c d . s e a s .} \cdot Z_{c . s e a s}}{\varepsilon}
$$

where:

$Q_{\text {V.sum. }}$ - cooling demand of summer time ventilation fresh air cooling, $\mathrm{kW}$,

$m_{\text {cd.seas. }}=0.5-$ summertime variable cooling demand averaging factor,

$Z_{c . s e a s}-$ duration of summer cooling season, assumed $Z_{c . s e a s}=1500 \mathrm{~h}$.

$\varepsilon$ - energy efficiency ratio of the refrigerator of air conditioner.

Substitution the values in formula (46) for given values gives the following seasonal electricity consumption by air conditioners of ordinary system for summer cooling: 


$$
N_{\text {sum.air.cond }}=\frac{(6.54+1.1) \cdot 0.5 \cdot 1500}{2.9}=1976 \mathrm{kWh} / \mathrm{seas} .
$$

while hybrid system's heat pump annually consumes $3844 \mathrm{kWh} /$ year of electricity. Cost of annual consumption of electricity by air conditioners makes $U_{\text {el.cond. }}=1976 \times 0.08=$ $\$ 158$. Annual repair cost of ordinary system makes $6370 x 0.04=255$ \$/year. So, total annual operation cost of ordinary system makes

$$
\Sigma U_{\text {ord }}=908.5+158+255=1318 \$ / \text { year. }
$$

Annual expenditures on ordinary system are:

$$
T=6370 / 25+1318=1573 \$ / \text { year }
$$

and specific cost of annual heating and cooling, referred to $1 \mathrm{~m}^{2}$ of building, $T_{s}, \$ / \mathrm{m}^{2}$ per year makes

$$
T_{s}=1573 / 144=10.9, \$ / \mathrm{m}^{2} \text { year. }
$$

\begin{tabular}{|c|c|c|}
\hline Characteristics & Hybrid system & Ordinary system \\
\hline Cost of heating boiler, $K_{\text {boil }}, \$$ & $\$ 390$ & $\$ 650$ \\
\hline Cost of ventilation fresh air heating separate boiler, $K_{\text {sep.boil. }}, \$$ & $\$ 320$ & $\$ 320$ \\
\hline Cost of ventilation fresh air heating equipment, $K_{H E X . V}, \$$ & $\$ 56$ & $\$ 56$ \\
\hline Cost of heat pump, $K_{H P}, \$$ & $\$ 1628$ & - \\
\hline Cost of winter condenser for intermediate worming of heating water, $K_{\text {cond }}, \$$ & $\$ 96$ & - \\
\hline Cost of solar air heater, $K_{\text {sol.heat. }}, \$$ & $\$ 469$ & - \\
\hline Cost of ordinary air conditioners for summer cooling, $K_{A C}, \$$ & - & $\$ 3056$ \\
\hline Cost of waste gases mixing chamber, $K_{\text {mix.chamb }}, \$$ & $\$ 72$ & - \\
\hline Cost of heating-cooling fan coils $K_{\text {fan-coil }}, \$$ & $\$ 268$ & $\$ 268$ \\
\hline Cost of automation system, $K_{\text {aut.syst }}, \$$ & $\$ 200$ & $\$ 200$ \\
\hline Total capital cost, $\sum K x 1,4, \$$ & $3499 \times 1,4=\$ 4899$ & $4550 \times 1,4=\$ 6370$ \\
\hline $\begin{array}{l}\text { Total cost of seasonal consumption of gas for heating and ventilation, } U_{\text {gas }} \text {, } \\
\$ / \text { seas, }\end{array}$ & $1834,7 \times 0,035=614 \$ /$ seas & $2712 \times 0,335=908,5 \$ /$ seas \\
\hline $\begin{array}{l}\text { Heat pump's electricity consumption for heating in heating season, } \\
N_{H P . \text { wint.seas. }}, \mathrm{kWh}\end{array}$ & $1868 \mathrm{kWh}$ & - \\
\hline $\begin{array}{l}\text { Heat pump electricity consumption for cooling and ventilation in cooling } \\
\text { season, } N_{\text {el.cooling.summ. }}, \mathrm{kWh}\end{array}$ & $1976 \mathrm{kWh}$ & $\begin{array}{l}\text { (el.consumption of air conditioners) } \\
1976 \mathrm{kWh}\end{array}$ \\
\hline Heat pump's annual consumption of electricity, $N_{H P \text {.аnпиal }}, \mathrm{kWh}$ & $1868+1976=3844 \mathrm{kWh}$ & - \\
\hline $\begin{array}{l}\text { Cost of annual consumption of electricity by heat pump, } \\
U_{\text {el.HP.ann. }}\left(U_{\text {el.air.cond.ann }}\right) \$ / \text { year }\end{array}$ & $3844 \mathrm{kWh} \times 0,08 \$ / \mathrm{kWh}=308 \$ /$ year & $1976 \mathrm{kWh} \times 0,08 \$ / \mathrm{kWh}=158 \$ /$ year \\
\hline Annual cost of current repair of the system, $U_{\text {rep. }}, \$ /$ year & $4899 \times 0.04=196 \$ /$ year & $6370 \times 0,04=255 \$ /$ year \\
\hline Total annual operational cost of system $\Sigma U, \$ /$ year & $614,6+308+196=1119$ \$/year & $908,5+158,3+255=1318 \$ /$ year \\
\hline Annual expenditures for running the system, $T$, & $T=4899 / 25+1119=1315 \$ /$ year & $T=6370 / 25+1318=251+1318=1573$ \\
\hline
\end{tabular}

The energy and cost characteristics of hybrid system are summarized in table 3 .

Table 3. The energy and cost characteristics of hybrid and ordinary systems

Analysis of data of table 3 shows that the specific cost of annual heating and cooling referred to $1 \mathrm{~m}^{2}$ of building, $T_{s}$, $\$ / \mathrm{m}^{2}$ per year for developed hybrid system in $1,79 \$ / \mathrm{m}^{2}$ year or in $20 \%$ is less compared to ordinary system. Therefore, wide application of developed hybrid system will provide significant savings of energy and means.

\section{Conclusions}

1. Research proves possibility of use warm waste gases mixture as low potential source for "gas mixture -air" new type heat pump.

2. The algorithm and mathematical model allow optimizing all characteristics of the hybrid system for variable values of loads of heating boiler $\beta$ and heat pump ( $1-\beta$ ) in the range $\beta=4 \div 6$.

3. Analysis showed rather high energy efficiency and reliability of such kind of heat pump and possibility of its efficient use in developed hybrid system of heating and cooling.

4. Suggested hybrid system of heating and cooling and developed method of its calculation allow designing and implementing energy efficient and cost effective heating and cooling of buildings.

5. Analysis of data, obtained based on method for revealing energy efficiency and cost effectiveness criteria shows that the specific cost of annual heating and cooling referred to $1 \mathrm{~m}^{2}$ of building, $T_{s}, \$ / \mathrm{m}^{2}$ per year for hybrid system in $1,79 \$ / \mathrm{m}^{2}$ year or in $20 \%$ is less compared to widely used ordinary systems. 
6. Wide application of developed hybrid system will provide significant savings of energy and means.

\section{References}

[1] Z. Melikyan, "Heating Cooling of Buildings. Efficiency of conventional and renewable technologies," LAP Lambert Academic Publishing, Germany, 2012, 345p, ISBN:978-3-8443 -1939-2

[2] Z. Melikyan, "Residential Buildings: Heating Loads," Encyclopedia of Energy Engineering and Technology, Taylor and Francis: New York, Published online: 2008, pp.1272-1277

[3] Z. Melikyan, V. Nranyan, "Solar Water Heaters: Cylindrical Shell-and-Tube Type," Encyclopedia of Energy Engineering and Technology, Taylor and Francis: New York, Published online: $2013,8 \mathrm{p}$.

[4] S. Egnatosyan, "Hybrid System For Heating and Cooling of Houses with "Air to Air" Heat Pump and Heating Boiler," The 4th International Renewable and Clean Energy Conference, Yerevan, 2009, p.41.

[5] 2013 ASHRAE Handbook-Fundamentals. Chapter: 30-Thermophysical properties of refrigerants. Mark S. Owen Editor, 2013, 76p

[6] Z. Melikyan, S. Egnatosyan, "Heating and Cooling Hybrid System with Gas Mixture Sourced Heat Pump and Heating Boiler," Journal of Energy and Power Engineering, Vol.5, N11, Serial Number 48, USA, 2011, pp.1021-1029

[7] Z. Melikyan, A.Fouda, "Assessment of a modified method for determining the cooling load of residential buildings," International Journal Elsevier V.35, England, Published online:. 2010, pp.4726-4730.

[8] M. Shogolev, "Fuel, furnace and boilers," State publishing house on architecture and construction, Moscow, 1953, 546p. (Published in Russian)

[9] P. Kamenev, "Heating and ventilation," Publishing house on construction, Moscow, 1964, 466p. (Published in Russian) 